\title{
Correction to: Contemporary cemented versus uncemented hemiarthroplasty for the treatment of displaced intracapsular hip fractures: a meta-analysis of forty-two thousand forty-six hips
}

\begin{abstract}
Mohamed A. Imam ${ }^{1} \cdot$ Mohamed S. A. Shehata ${ }^{2,3} \cdot$ Ahmed Elsehili $^{2} \cdot$ Mahmoud Morsi $^{4} \cdot$ Alexander Martin $^{5,9} \cdot$ Muhammad Shawqi $^{6} \cdot$ Florian Grubhofer $^{7} \cdot$ Nish Chirodian $^{1} \cdot$ Ali Narvani $^{8} \cdot$ Lukas Ernstbrunner $^{7}$
\end{abstract}

Published online: 7 May 2019

(C) SICOT aisbl 2019

\section{Correction to: International Orthopaedics}

https://doi.org/10.1007/s00264-019-04325-x

The published online version contains a mistake.

The author name "Muhammad Shawqi" was incorrectly presented as "Muhammad Shawq". The correct presentation is given above.

The original article has been corrected.

Publisher's note Springer Nature remains neutral with regard to jurisdictional claims in published maps and institutional affiliations.

The online version of the original article can be found at https://oi.org/ 10.1007/s00264-019-04325-x

\section{Alexander Martin}

alexandermartin@nhs.net

Norfolk and Norwich University Hospitals, Norwich, England

2 Faculty of Medicine, Zagazig University, Zagazig, Egypt

3 Medical Research Group of Egypt, Cairo, Egypt

4 Faculty of Medicine Menoufia University, Menoufia, Egypt

5 Oxford University Hospitals NHS Foundation Trust, Oxford, UK

6 Faculty of Medicine, Assuit University, Asyut, Egypt

7 Balgrist University Hospital, University of Zurich, Zurich, Switzerland

8 Ashford and St Peter's NHS Trust, Ashford, Kent, UK

9 London, UK 